\title{
Definition of design criteria of mechanical transfer: an interaction between engineering and health areas
}

\author{
Taciana Ramos Luz ${ }^{a^{*}}$ and Eliza Helena de Oliveira Echternacht ${ }^{\mathrm{b}}$ \\ ${ }^{a}$ Department of Production Engineering, Federal University of Minas Gerais, Av. Antônio Carlos, 6627 - \\ Laboratório Integrado de Produção e Saúde (LIPES) - sala 3300, MG, Brazil. \\ ${ }^{\mathrm{b}}$ Department of Production Engineering, Federal University of Minas Gerais, Av. Antônio Carlos, 6627 - \\ Laboratório Integrado de Produção e Saúde (LIPES) - sala 3300, MG, Brazil.
}

\begin{abstract}
This study aims to analyze the factors that justify the low use of a mechanical transfer in the context of a long-term institution. It is a device intended for internal transportation of individuals who have mobility problems. The analysis involves researchers from the fields of health and engineering in order to generate design criteria that consider the needs of caregivers and patients of this institution. To understand the reality of this site and their specificities, was used Ergonomic Work Analysis.
\end{abstract}

Keywords: mechanical transfer, elderly, ergonomics, sling, transfer

\section{Introduction}

The mechanical transfer is a device that aims to facilitate transfer from wheelchair to bed, bath or toilet and some models have the ability to move the patient from the floor. It is indicated for internal transportation of individuals who have mobility problems as the disabled and elderly. It consists of a metal frame and a sling (tissue in which it lodges the person being transported). Your actuation may be hydraulic or electric. One type of hydraulic mechanical transfer is represented in Figure 1.

Currently, one can find numerous scientific evidences showing that the use of the mechanical transfer can prevent the onset of occupational musculoskeletal disorders in nurses or caregivers, both in long-stay institutions as in hospitals. Some references $[2,3,5-8,10,12-13]$ indicated that manual transfer increases the compressive forces between vertebrae L5 and S1, and this compression is even greater when the transfer is performed by just one person. Nevertheless, the mechanical transfers are rarely used due to lack of space, need of maintenance, because it is considered unstable and insecure, difficulty of placing and removing the sling and due to the fear of patients $[1,9,11]$

This study aims to analyze the reasons for low use, by caregivers, of the mechanical transfer to aid in transferring in a long-term institution, to generate design criteria discussed among researchers in health and engineering that address the specific situations of use of this equipment.

The three caregivers analyzed are nursing assistants and its activities include: transportation of dependent patients, help in the feeding of bedridden patients, swap of diapers and bathing.

\footnotetext{
Corresponding author. E-mail: tacianaluz@hotmail.com
} 


\section{Methods}

This ongoing study uses the Ergonomic Work Analysis [4], which enables you to perform an analysis of activity and get information, through observations and interviews, about the specifics of the actual work situations.
Three visits were conducted to the local to observe the context of patients transfer situations, beyond simultaneous interviews with three patients and four caregivers.

In addition, records were made in photo and video by permission.

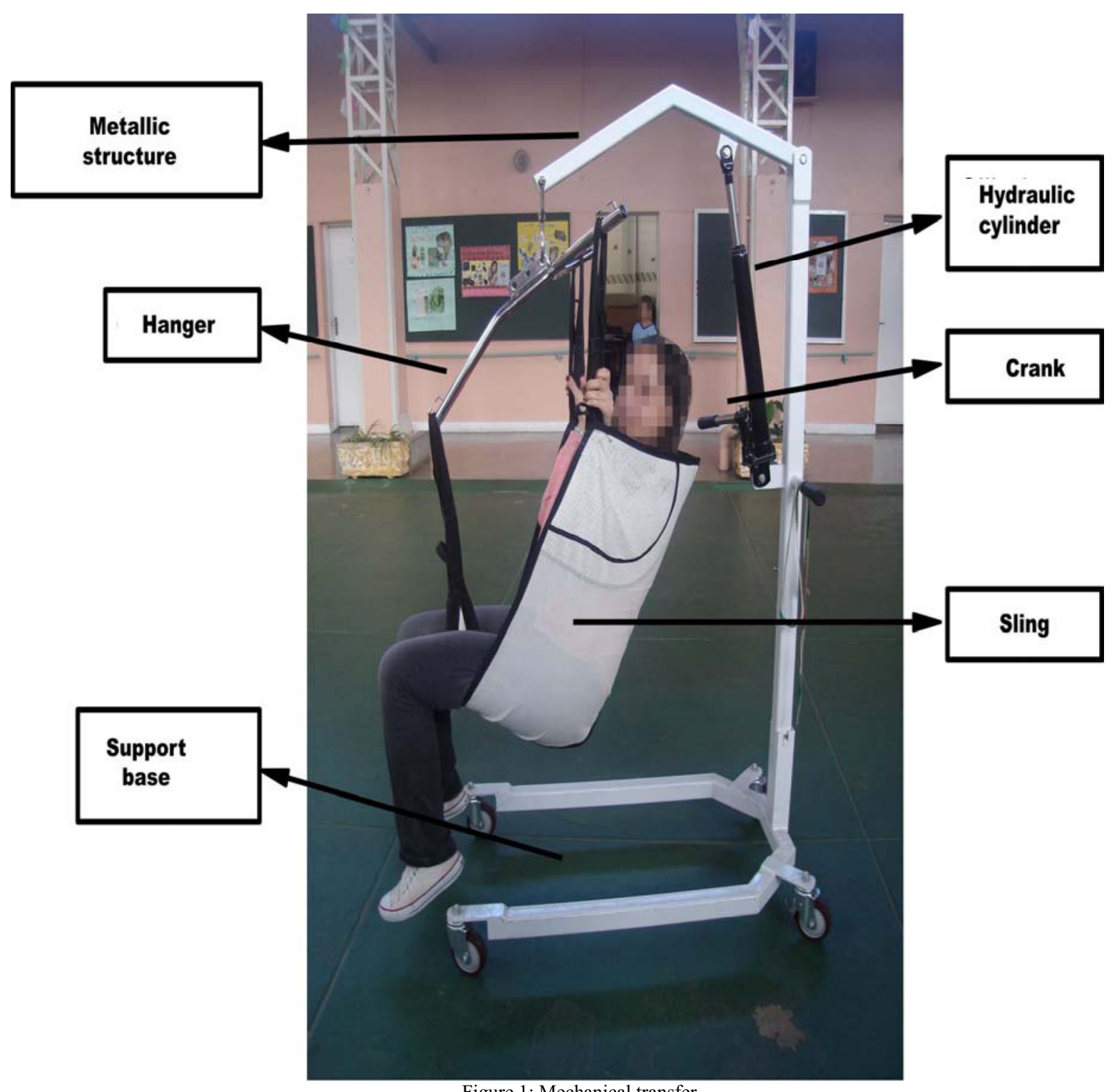

Figure 1: Mechanical transfer

These visits were conducted in Belo Horizonte city in the period from July 2010 to May 2011. In 2010, there were two visits in order to collect data about the location. In May 2011, two more visits were realized to confirm the information collected in the previous period, and it was found that the same problems persisted. 
The caregivers are aged between 20 and 55 years, and two are female. These were randomly selected during visits and after their consent. The patients are aged between 60 and 95 years and have limited mobility, necessitating the use of a wheelchair.

Were measured in minutes the time of manual transfer of three elderly people from bed to wheelchair and with the use of mechanical transfer in a specific situation: transfer from the bath for wheelchair. In addition, was counted the number of actuates the crank need to lift the patient on the mechanical transfer.

\section{Results}

The training for caregivers is directed to conduct manual transfers. The manual transfer is made by only one caregiver when the patient is cooperative, and two caregivers, when the patient is obese and / or does not respond to commands. In only one of the situations observed, the mechanical transfer was used: an elderly transferred from bathtub to a wheelchair. It was also possible to observe that these caregivers are beneath to time pressure, because, reportedly, there were several tasks to be accomplished with other patients in a short period of time.

In the institution analyzed, two mechanical transfers housed in a room next to a bathroom and one is used in cases of risk of falling, as in the wet surface of the bathroom, according to the case observed where only one of mechanical transfers were used, to transfer to the bathtub from wheelchair.

The reasons for low use identified by respondents were:

\subsection{Longest transfer time using the mechanical transfer and the need for excessive movement of the crank}

The average time taken for manual transfer is a maximum of 1 minute and about 6 minutes to transfer with mechanical transfer, including the placement of the sling under the patient. In addition, there is an increased rigidity of the crank in the case of heavier patients, according to the report of a caregiver:

"The sling of mechanical transfer takes long time to move up, it has to move the handle several times and depending on the weight of the person, it is labourious." Caregiver of the Institution

\subsection{No head restraint and seat belt}

The mechanical transfer, rather than be a help the elderly that are highly dependent and are not cooperative during transfers, it is contraindicated. The lack of support of the trunk, especially of the cervical spine, can cause injury and increase the feeling of fear and insecurity of the individual to be transported. Likewise, the lack of seat belt leads to increased risk of falls.

"The sling had to support the entire body, miss head restraint. I cannot use for the elderly that are totally dependents, only for those who are cooperative." Caregiver of the Institution

"It should have a belt to give more security" Caregiver of the Institution

"I do not go up in this thing, it's scary, and then, who gets hurt is me."

Patient Interviewed

\subsection{Unsuitability of the wheels on uneven surfaces and curves}

The wheels of this mechanical transfer rotate the satisfactorily in the perfectly regular surfaces and that has no curves. However, on uneven surfaces, an additional effort is necessary, because caregiver need to sustain the patient and the mechanical transfer arms to transpose some obstacle. In addition, we observed that the wheels catch in curves, generating a surplus labor from the caregiver who needs to use force to move it.

"Through the doorway of the bathroom, I have to sustain the mechanical transfer and the patient, because the marble bathroom door, that was done to prevent the passage of water out, do not allows the wheels goes pass."

Caregiver of the Institution

"It's difficult to change the direction of the mechanical transfer, the wheels do not turn to follow the movement."

Caregiver of the Institution

\subsection{Need for constant positioning of the patient during transport}

With the mechanical transfer in movement, the patient, along with the sling features a rotating movement around the pivot axis of the hanger support; this individual will have to be readjusted before passing it through tight spots, such as doors. 
"To go with the person through the door, we have to adjust the patient, to not to pass skewed, because the patient can knocking at the door."

Caregiver of the Institution
According to the collected information, researchers in the areas of health and engineering are developing a prototype that considers the opinions of the users. After meetings and discussions on the theme, these solutions are in the Table 1.

Table 1

Definition of design criteria according to the factors raised in the research

\begin{tabular}{|l|l|}
\hline Facts raised & \multicolumn{1}{|c|}{ Design Criteria } \\
\hline $\begin{array}{l}\text { 1. Longest transfer time using the protractor and } \\
\text { need for excessive movement of the crank. }\end{array}$ & $\begin{array}{l}\text { Install a pedal instead of hand crank so that the caregiver's hands } \\
\text { becomes frees for adjustments; } \\
\text { Hydraulic cylinder must inevitably have a larger course to allow a } \\
\text { greater upward shift }\end{array}$ \\
\hline $\begin{array}{l}\text { 2. No head restraint and seat belt. } \\
\text { 3. Unsuitability of the wheels. }\end{array}$ & $\begin{array}{l}\text { Configuration of the sling with head support and seat belt. } \\
\text { Search for models of wheels able to perform curves and able to } \\
\text { transpose the irregularities of the soil. }\end{array}$ \\
$\begin{array}{l}\text { 4. Need for constant positioning of the patient } \\
\text { during transport }\end{array}$ & $\begin{array}{l}\text { Attach a strap in a sling and in metal frame so that the patient does } \\
\text { not rotate during transport }\end{array}$ \\
\hline
\end{tabular}

\section{Discussion and conclusion}

From these results, it is necessary to emphasize the importance of observing the situations of use for developing design criteria for mechanical transfers; the following aspects are fundamental: adaptation to irregularities of the soil and ability to make curves, consider the profiles of users (children or elderly who have no trunk control), maintain the stability of the sling during transport to the patient does not rotate in pivot, review mechanisms to reduce the transfer time of the mechanical transfer.

Therefore, it is important to the interaction between researchers in the areas of health and engineering to analyze the profile of users of the equipment and for definition of adequacies. This reflection can serve subsidy to the causes of non-use of mechanical transfers existing in other institutions.

\section{References}

[1] Bell, F.; Dalgity, M.E.; Fennel, M.J.; Aitken, R.C. Hospital Ward Patient-lifting Tasks. Ergonomics, v.22, p.1257-1273, 1979.

[2] Evanoff, B.; Wolf,L.; Aton,E.; Canos,J.; Colins,J. Reduction in Injury Rates in Nursing Personnel Through Introduction of Mechanical Lifts in the Workplace. American Journal of Industrial Medicine. v.44, p.451-457, 2003.

[3] Garg, A.; Owen, B.; Beller,D.; Banaag, J. A Biomechanical and Ergonomic Evaluation of Patient Transferring Tasks: Bed to Wheelchair and Wheelchair to Bed. Ergonomics, v.34, n.3, p.289-312, 1991 .

[4] Guérin, F.; Laville, A.; Daniellou, F.; Durrafourg, J.; Kerguellen, A. Compreender o trabalho para transformálo: a prática da Ergonomia. $1^{\mathrm{a}}$ ed. São Paulo: Edgard Bucher. 2001.200 p.

[5] Hignett, S.; Crumpton, E.; Ruszala, S.; Alexander, P.; Fray, M.; Fletcher, B. Evidence based patient handling: systematic review. Nursing Standard, v.17, n.33, p.33-36, 2003.

[6] Lloyd, J.D. Biodynamics of back injury: manual lifting and loads. In: Charney, W., Hudson, A. Back Injury Among Healthcare Workers: Causes, Solutions, and Impacts. Lewis Publishers: Boca Raton, 2004. p. 27-35.

[7] Marras, W.S.; Davis, K.G.; Kirking, B.C.; Bertsche, P.K. A comprehensive analysis of low-back disorder risk and spinal loading during the transferring and repositioning of patients using different techniques. Ergonomics, v.42, n.7, p.904-926, 1999a. 
[8] Miller, $\bullet$ A.; Engst, $\bullet$ C.; Tate, R.B.; Yassi, $\bullet$ A. Evaluation of the effectiveness of portable ceiling lifts in a new long-term care facility. Applied Ergonomics. v.37, p.377-385, 2006.

[9] Owen, BD. Patient Handling Tasks Perceived to be Most Stressful by Nursing Assistants. In: A. MITAL. Advances in Industrial Ergonomics and safety. Taylor \& Francis: London, 1988.p. 775-781

[10] Owen, B.D.; Keene, K.; Olson, S.; Garg, A. An ergonomic approach to reducing back stress while carrying out patient handling tasks with a hospitalized patient. In: Hagberg M, Hofmann F, Stoessel U, Westlander G, editors. Occupational health for health care workers. Landsberg, Germany: Ecomed, 1995.p. 102-107.
[11] Takala, EP; Kukkonen, R. The handling of Patients of Geriatric Wards. A Challenge for On-the-job Training. Applied ergonomics, v.18, p.17-22, 1987.

[12] Zhuang, Z.; Stobbe, T.J.; Hsiao, H.; Collins, J.W.; Hobbs, G.R. Biomechanical evaluation of assistive devices for transferring residents. Applied Ergonomics. v.30, p.285294, 1999

[13] Zhuang, Z.; Stobbe, T.J.; Hsiao, H.; Collins, J.W.; Hobbs, G.R. Psychophysical assessment of assistive devices for transferring patients/residents. Applied Ergonomics. v.31, p. $35-44,2000$ 